\title{
Association Between the Distributions of Mean Corpuscular Hemoglobin and Red Blood Cell, and Mortality in a 3-Year Retrospective Study of Hemodialysis Patients
}

\author{
Yoshihiro Tsuji ${ }^{1, ~ *}$, Yasumasa Hitomi ${ }^{2}$, Naoki Suzuki ${ }^{2}$, Yuko Mizuno-Matsumoto ${ }^{3}$, Toshiko Tokoro ${ }^{4}$, \\ Masato Nishimura ${ }^{5}$ \\ ${ }^{1}$ Department of Medical Engineering, Faculty of Health Sciences, Morinomiya University of Medical Sciences, Osaka, Japan \\ ${ }^{2}$ Department of Clinical Engineering, Tojinkai Hospital, Kyoto, Japan \\ ${ }^{3}$ Graduate School of Applied Informatics, University of Hyogo, Kobe, Japan \\ ${ }^{4}$ Department of Nephrology, Tojinkai Satellite Clinic, Kyoto, Japan \\ ${ }^{5}$ Cardiovascular Division, Tojinkai Satellite Clinic, Kyoto, Japan
}

Email address:

yoshihiro_tsuji@morinomiya-u.ac.jp (Y. Tsuji)

*Corresponding author

\section{To cite this article:}

Yoshihiro Tsuji, Yasumasa Hitomi, Naoki Suzuki, Yuko Mizuno-Matsumoto, Toshiko Tokoro, Masato Nishimura. Association Between the Distributions of Mean Corpuscular Hemoglobin and Red Blood Cell, and Mortality in a 3-Year Retrospective Study of Hemodialysis Patients. International Journal of Biomedical Engineering and Clinical Science. Vol. 6, No. 2, 2020, pp. 41-47. doi: 10.11648/j.ijbecs.20200602.13

Received: May 4, 2020; Accepted: June 15, 2020; Published: June 29, 2020

\begin{abstract}
Introduction: A red blood cell (RBC) concentration of 300 to $350 \times 10^{4} / \mu \mathrm{L}$ and mean corpuscular hemoglobin (MCH) concentration of 30 to $35 \mathrm{pg}$ have been proposed as management target values from the relationship of $\mathrm{Hb}=\mathrm{RBC} \times \mathrm{MCH}$ to control anemia, wherein $\mathrm{Hb}$ levels should not exceed $12 \mathrm{~g} / \mathrm{dL}$. In contrast, even in patients whose Hb levels are maintained at 10 to 12 $\mathrm{g} / \mathrm{dL}, \mathrm{Hb}$ levels are widely distributed when divided into $\mathrm{RBC}$ and $\mathrm{MCH}$. Objective: We examined the prognosis in the distribution of $\mathrm{MCH}$ and RBC. Methods: Patients were classified into two groups based on $\mathrm{MCH}$ and $\mathrm{RBC}$ values, wherein patients with $\mathrm{MCH} \geq 30 \mathrm{pg}$ but $<35 \mathrm{pg}$ and $\mathrm{RBC} \leq 350 \times 10^{4} / \mu \mathrm{L}$ (Group I, $\mathrm{n}=177$ ); and $\mathrm{MCH}<30 \mathrm{pg}$ and $\mathrm{RBC}>350 \times 10^{4} / \mu \mathrm{L}$ (Group II, $\mathrm{n}=217$ ). Associations between all-cause mortality and the distributions of $\mathrm{MCH}$ and $\mathrm{RBC}$ as well as the iron profiles of these two groups were assessed by Kaplan-Meier curves and Cox proportional hazards regression model, respectively. Results: Patients with $\mathrm{MCH}<30 \mathrm{pg}$ and $\mathrm{RBC}>350 \times 10^{4} / \mu \mathrm{L}$ (Group II, $\mathrm{n}=217$ ) had an increased long-term risk of death and a higher rate of iron deficiency than patients with $\mathrm{MCH} \geq 30 \mathrm{pg}$ but $<35 \mathrm{pg}$ and $\mathrm{RBC} \leq 350 \times 10^{4} / \mu \mathrm{L}$ (Group I, $\mathrm{n}=177$ ). Conclusions: The management

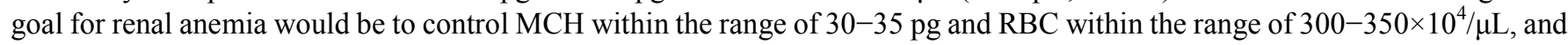
to avoid absolute iron deficiency.
\end{abstract}

Keywords: Anemia Management, Hemodialysis, Hemoglobin, Mean Corpuscular Hemoglobin, Red Blood Cell

\section{Introduction}

Anemia is common in patients receiving hemodialysis (HD) and is associated with poor clinical outcomes [1]. Therefore, erythropoietin-stimulating agents (ESA) and intravenous iron administration (therapy) have a key role in the clinical practice of anemia management among patients undergoing HD. The Guidelines for Renal Anemia in Chronic Kidney Disease of 2015 Japanese Society for Dialysis Therapy recommend administration when hemoglobin $(\mathrm{Hb})$ levels $\geq 10 \mathrm{~g} / \mathrm{dL}$ but $<12 \mathrm{~g} / \mathrm{dL}$ in dialysis patients [2]. However, it does not specifically describe how to use the ESA and the iron agent to achieve these $\mathrm{Hb}$ levels. The setting of red blood cell (RBC) 300 to $350 \times 10^{4} / \mu \mathrm{L}$ and mean corpuscular hemoglobin $(\mathrm{MCH}) 30$ to $35 \mathrm{pg}$ as management target values from the relationship of $\mathrm{Hb}=\mathrm{RBC}$ $\times \mathrm{MCH}$ as anemia control has been proposed, wherein $\mathrm{Hb}$ levels do not exceed $12 \mathrm{~g} / \mathrm{dL}$.

$\mathrm{The} \mathrm{Hb}$ levels generally provide the value of $\mathrm{RBC}$ and iron status as $\mathrm{MCH}$ value is obtained by dividing the $\mathrm{Hb}$ by $\mathrm{RBC}$ 
value. $\mathrm{MCH}$ depends on the size and concentration of erythrocytes. Thus, RBC and $\mathrm{MCH}$ values depend on dose of ESA and iron, respectively. Hb levels are represented by the product of the number of $\mathrm{RBC}$ and the average amount of $\mathrm{MCH}$, which is one of the RBC constants. Specifically, since $\mathrm{Hb}=\mathrm{RBC} \times \mathrm{MCH}$, when $\mathrm{Hb}=10$ or $12 \mathrm{~g} / \mathrm{dL}$, it is possible to draw a constant curve by applying this formula. Moreover, there is an upper limit on the number of hemoglobin that can be contained in a single RBC, and $\mathrm{MCH}$ does not exceed 35 pg in most patients. These results suggest that $\mathrm{Hb}$ levels can be stably maintained by controlling the RBC to 300 to $350 \times 10^{4} / \mu \mathrm{L}$ by ESA and the $\mathrm{MCH}$ to 30 to $35 \mathrm{pg}$ by iron supplementation. However, despite properly controlling $\mathrm{Hb}$ levels, the difference in prognosis, whether or not it falls within this range, remains unclear. Thus, even if $\mathrm{Hb}$ levels are adjusted in the range of $10-12 \mathrm{~g} / \mathrm{dL}, \mathrm{RBC}$ and $\mathrm{MCH}$ values are considered to vary. There are no reports on $\mathrm{RBC}$ values, $\mathrm{MCH}$ values, and prognosis; hence, recent reports on the prognostic impact of transferrin saturation (TSAT), which is thought to be related to $\mathrm{MCH}$, were examined for possible effects of $\mathrm{MCH}$ on prognosis.

\section{Methods}

\subsection{Ethical Considerations}

The Ethics Committee for Human Research of Tojinkai Hospital approved this study. Informed consent was obtained from all individual participants included in the study. All procedures performed in studies involving human participants were in accordance with the ethical standards of the institutional and national research committee at which the studies were conducted (IRB approval number NCT04227158) and with the 1964 Helsinki Declaration and its later amendments or comparable ethical standards.

\subsection{Patient and Study Measurements}

We enrolled 437 patients (mean age, 71.0 \pm 12.2 years; women, $42 \%$; mean duration of $\mathrm{HD}, 11.8 \pm 9.2$ years) who were controlled with hemoglobin levels between $\geq 10 \mathrm{~g} / \mathrm{dL}$ and $<12 \mathrm{~g} / \mathrm{dL}$ and had undergone maintenance HD for $>1$ year at Tojinkai Hospital, Kyoto, Japan. We examined data from all individuals who underwent maintenance HD treatment three times weekly from 1 December 2015 to 31 December 2018. Patients were excluded if they had peritoneal dialysis combined with HD, did not have records of laboratory investigations during this period, or were transferred to another hospital or lost to follow-up.

We collected data regarding the demographic characteristics, patients' age, sex, dialysis duration, diabetes mellitus (DM) history, cardiovascular disease (CVD) history, height, dry weight (DW), body mass index (BMI), dialysis mode (HD of Online HDF), HD time, systolic and diastolic boiled pressure, HD dose $\left(\mathrm{Kt} / \mathrm{V}_{\text {ure }}\right)$, erythropoietin resistance index (ERI) at baseline (1 December 2015), and geriatric nutritional risk index (GNRI). CVD included the presence of ischemic heart disease, peripheral vascular disease, and cerebral vascular disease.

The DW was determined clinically and reflected the lowest weight that the patient could tolerate without intradialytic symptoms, hypotension, and overt fluid overload. The DW was continuously updated according to the medical doctors' changes in orders throughout the observation period. The BMI was calculated as the patient's DW divided by the square of the patient's height. The $\mathrm{Kt} / \mathrm{V}_{\text {ure }}$ was determined according to single-pool urea kinetics models [3]. ERI was calculated by dividing the total weekly erythropoietin dose by the patient's DW and patient's $\mathrm{Hb}$ level. The lower the result, the more sensitive is the response to recombinant human erythropoietin (rHuEPO). Conversely, a high ERI indicates relative resistance to rHuEPO erythropoietic effects [4]. The ideal body weight was calculated from the height and a BMI of 22 [5].

Biochemical parameters such as $\mathrm{Hb}$ levels, $\mathrm{RBC}, \mathrm{MCH}$, mean corpuscular volume (MCV), $\mathrm{MCH}$ concentration (MCHC), serum ferritin levels, TSAT, serum iron levels, total iron binding capacity (TIBC), unsaturated iron binding capacity (UIBC), serum albumin levels, blood urea nitrogen (BUN), serum creatinine levels ( $\mathrm{Cr}$ ), serum calcium levels, serum inorganic phosphorus levels, and high-sensitivity C-reactive protein (CRP) were obtained. Serum iron levels and CRP were measured using the Nitroso-PSAP method and the latex agglutination turbidimetry method, respectively. TSAT was calculated as serum iron divided by TIBC. Blood samples $(4 \mathrm{~mL})$ were obtained immediately before the HD session began for pre-HD measurements and at the end of the HD session for post-HD measurements on the first day of the week.

\subsection{Statistical Analysis}

All data are expressed as means and standard deviation (SD), or medians and interquartile range (IQR). Categorical variables were assessed with Fisher's exact probability test or Mann-Whitney's $U$ test as appropriate. Firstly, the 394 patients were classified into two groups based on the values of $\mathrm{MCH}$ and RBC: patients with $\mathrm{MCH} \geq 30 \mathrm{pg}$ but $<35 \mathrm{pg}$ and $\mathrm{RBC} \leq 350 \times 10^{4} / \mu \mathrm{L}$ (Group I, $\mathrm{n}=177$ ); and $\mathrm{MCH}<30 \mathrm{pg}$ and $\mathrm{RBC}>350 \times 10^{4} / \mu \mathrm{L}$ (Group II, $\mathrm{n}=217$ ) to assess the mortality and the association between the distributions $\mathrm{MCH}$ and $\mathrm{RBC}$. Secondly, among Groups I and II, patients were further divided into 4 subgroups based on TSAT and serum ferritin values to assess the iron status of patients. Here, we used cut-off values for serum ferritin levels and TSAT of 100 $\mathrm{ng} / \mathrm{mL}$ and $20 \%$, respectively. The four subgroups were as follows: Q1, serum ferritin levels $\geq 100 \mathrm{ng} / \mathrm{dL}$, TSAT $\geq 20 \%$; Q2, serum ferritin levels $<100 \mathrm{ng} / \mathrm{dL}, \mathrm{TSAT} \geq 20 \%$; Q3, serum ferritin levels $<100 \mathrm{ng} / \mathrm{dL}$, TSAT $<20 \%$; and Q4, serum ferritin levels $\geq 100 \mathrm{ng} / \mathrm{dL}, \mathrm{TSAT}<20 \%$. Japanese guidelines for renal anemia in chronic kidney disease recommend administration of iron to patients with serum ferritin levels $<100 \mathrm{ng} / \mathrm{mL}$ and with TSAT $<20 \%$ [2]. These are the values that the guidelines of 2015 Japanese Society for Dialysis Therapy for treating anemia in CKD recommend that iron be administered to 
patients [2]. Thirdly, patients were divided into two groups according to the presence or absence of iron deficiency, and $\mathrm{MCH}$ and $\mathrm{RBC}$ distribution were examined. Here, iron deficiency was defined as TSAT $<20 \%$ with ferritin levels $<100$ $\mathrm{ng} / \mathrm{mL}$ [2]. Finally, the correlation was investigated between TSAT and $\mathrm{MCH}$, and TSAT and RBC in 384 patients. Pearson's product-moment correlation coefficient was used to study the relationship between TSAT and $\mathrm{MCH}$, and TSAT and RBC.

Survival curves for 3-year survival, based on all available follow-up data, were constructed with the use of KaplanMeier estimates and compared between groups with use of the log-rank test, and used Holm's method as post hoc. Cox proportional hazards regression was used to examine predictors of the death in all patients, with patients' mean age, sex, dialysis duration, history of DM, history of CVD, BMI, serum albumin levels, CRP, and $\mathrm{Kt} / \mathrm{V}_{\text {ure }}$. The survival time for each patient was determined by the number of days from the start of this study to the end of the observation period or the date of the patient's death. The multicollinearity in the multivariable model was examined using regression diagnostic analysis. Furthermore, covariates were selected as those variables that might plausibly be associated with outcomes based on clinical precedent and evidence from the literature. $p$-values $<0.05$ indicated statistical significance. All statistical analyses were performed with $\mathrm{R}$ language (version 3.5.2).

\section{Results}

\subsection{Baseline Characteristics in the Distribution According to $M C H$ and $R B C$}

Demographic, clinical, and biochemical characteristics categorized by the values of $\mathrm{MCH}$ and $\mathrm{RBC}$ of the study population are shown in Table 1 . Among all patients, 177 with $\mathrm{MCH} \geq 30 \mathrm{pg}$ but $<35 \mathrm{pg}$ and $\mathrm{RBC} \leq 350 \times 10^{4} / \mu \mathrm{L}$ (Group I); 217 patients with $\mathrm{MCH}<30 \mathrm{pg}$ and $\mathrm{RBC}>350 \times 10^{4} / \mu \mathrm{L}$ (Group II). During the 3-year follow-up period, 25 patients (14\%) in Group I and 58 patients (27\%) in Group II died. Upon comparing Groups I and II, number of patients who survived, duration of survivals period, $\mathrm{MCH}, \mathrm{MCV}, \mathrm{MCHC}$, serum ferritin levels, TSAT, and ERI were found to be significantly higher among participants in Group I than those among Group II ( $p=0.0028, p=0.0008, p<0.0001, p<0.0001$, $p<0.0001, p<0.0001, p=0.0023, p=0.0109$, respectively). $\mathrm{Hb}$ levels, RBC, TIBC, and CRP were found to be significantly lower among participants in Group I than those among Group II $(p<0.0001, p<0.0001, p=0.0263, p<0.0001$, respectively). No differences were observed between Groups I and II regarding patients' age, sex, dialysis duration, with or without DM and CVD, mode (HD / On line HDF), HD time, systolic and diastolic blood pressure before HD, serum iron levels, UIBC, serum albumin levels, blood urea nitrogen, serum creatinine, serum calcium, serum inorganic phosphorus, Kt/ $\mathrm{V}_{\text {urea }}$, dose of ESAs IU/week, and GNRI (all, $p>0.05)$.

\subsection{Survival Curves in the Distribution According to $\mathrm{MCH}$}

Table 2 shows the results of Cox proportional hazard regression analysis. Data were adjusted for CRP selected as covariates to adjust all-cause death to avoid multicollinearity in the statistical analyses as CRP was associated with increased mortality (HR, 1.40; 95\% CI, 1.22-1.62, $p<0.0001$ ).

Figure 1 shows the survival curves adjusted for significant predictors at Cox proportional hazard regression analysis. During the follow-up period, 25 patients (14\%) in Group I and 58 patients (27\%) in Group II died, and the average survival periods (SD) were 1069 (174) and 975 (286) days, respectively. Survival curves were obtained using the Kaplan-Meier estimation method and compared using a log-rank test to determine the difference in survival rates between Groups I and II. The survival time for each patient was determined by the number of days from the start of this study to the end of the observation period or the date of the patient's death. With a follow-up of 3 years, a significantly greater patient mortality with $\mathrm{MCH}<30 \mathrm{pg}$ and $\mathrm{RBC}>350 \times 10^{4} / \mu \mathrm{L}$ (Group II) was observed ( $p=0.0014)$.

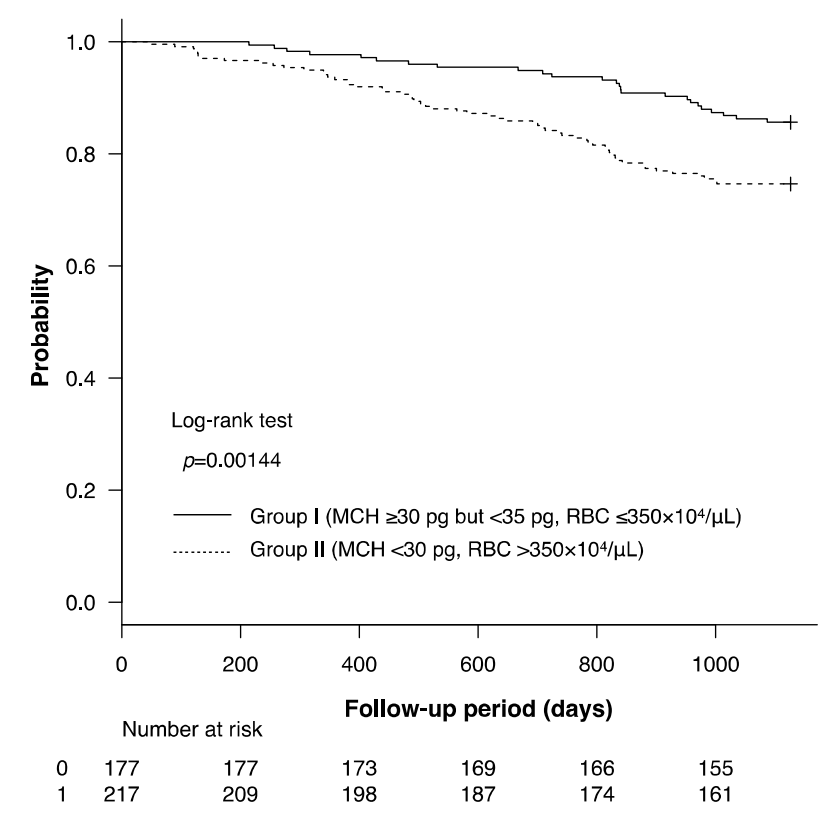

Figure 1. Survival curves according to the distribution of $M C H$ and $R B C$ during 3-year follow up periode.

Cox-adjusted survival during follow-up with regard to all-cause mortality in HD patients stratified by $\mathrm{MCH}$ and $\mathrm{RBC}$ values: Group I, $\mathrm{MCH} \geq 30 \mathrm{pg}$ but $<35 \mathrm{pg}$ and $\mathrm{RBC} \leq 350 \times 10^{4} / \mu$; Group II, $\mathrm{MCH}<30 \mathrm{pg}$ and $\mathrm{RBC}>350 \times 10^{4} / \mu \mathrm{L}$.

Table 3 shows the results of the distribution of group I $\left(\mathrm{MCH} \geq 30\right.$ pg but $<35 \mathrm{pg}$ and $\left.\mathrm{RBC} \leq 350 \times 10^{4} / \mu \mathrm{L}\right)$ and II $\left(\mathrm{MCH}<30 \mathrm{pg}\right.$ and $\left.\mathrm{RBC}>350 \times 10^{4} / \mu \mathrm{L}\right)$ according to serum ferritin levels and TSAT. Upon comparing both groups, the rate of TSAT $\geq 20 \%$ and serum ferritin levels $\geq 100 \mathrm{ng} / \mathrm{mL}$ were found to be significantly higher among participants in Group I than those among Group II $(p<0.0001)$. The rate of 
$\mathrm{TSAT}<20 \%$ and serum ferritin levels $<100 \mathrm{ng} / \mathrm{mL}$ were

\section{a}

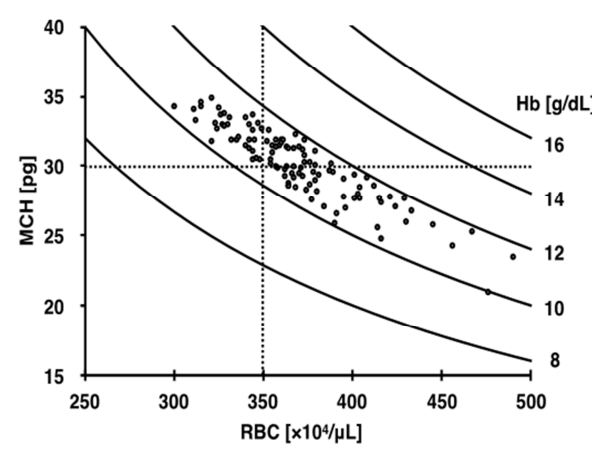

significantly lower in Group I than in Group II $(p<0.0001)$.

b

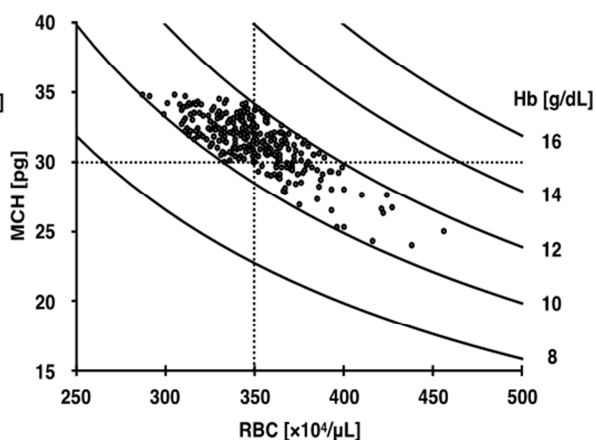

Figure 2. Distribution according to MCH and RBC in patients with or without iron deficiency.

Patients were categorized into two groups according to with or without iron deficiency as follows: (a), iron deficiency $(+)$ group, $\mathrm{n}=109$ (TSAT $<20 \%$, Ferritin $<100 \mathrm{ng} / \mathrm{mL}$ ); (b), iron deficiency (-) group, $\mathrm{n}=285 \quad(\mathrm{TSAT} \geq 20 \%$, Ferritin $\geq 100$ $\mathrm{ng} / \mathrm{mL})$. Comparing the proportion of patients with

\section{a}

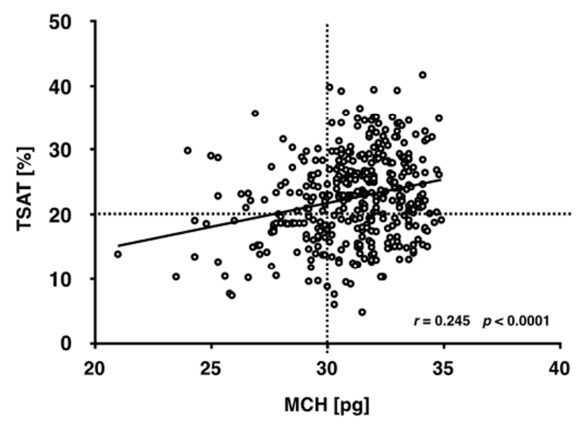

$\mathrm{RBC}>350 \times 10^{4} / \mu \mathrm{L}$ and $\mathrm{MCH}<30 \mathrm{pg}$ in the iron deficiency $(+)$ group $(n=48,[44 \%])$ and iron deficiency $(-)$ groups $(n=61$, $[21 \%]$ ), the proportion of patients with $\mathrm{MCH}<30 \mathrm{pg}$ and $\mathrm{RBC}>350 \times 10^{4} / \mu \mathrm{L}$ in iron deficiency $(+)$ group was significantly higher than in the iron deficiency $(-)$ group

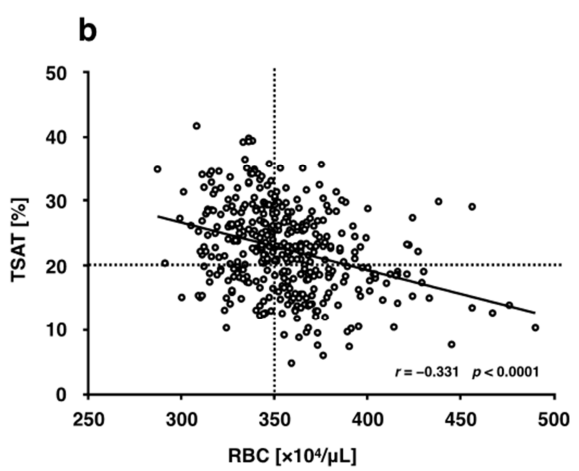

Figure 3. Correlation between TSAT and MCH (a), and between TSAT and RBC (b).

Pearson's product-moment correlation coefficient. A significant statistical positive correlation was observed between TSAT and MCH. Conversely, a significant statistical negative correlation was observed between TSAT and RBC. Pearson's correlation coefficient ( $\mathrm{r}$ ) and the corresponding $p$ values for these correlation were $\mathrm{r}=0.245$ and $\mathrm{r}=-0.331$, and $p<0.0001$ in both cases.

Figure 2 shows the results of the distribution of $\mathrm{MCH}$ and $\mathrm{RBC}$ in two groups according to the presence or absence of iron deficiency. Of 394 patients, 109 (iron deficiency $(+)$ group; TSAT $<20 \%$ and serum ferritin levels $<100 \mathrm{ng} / \mathrm{mL}$ ) had iron deficiency, and 285 had no iron deficiency (iron deficiency (-); group; TSAT $\geq 20 \%$ and serum ferritin levels $\geq 100 \mathrm{ng} / \mathrm{mL}$ ). Comparing the proportion of patients with $\mathrm{RBC}>350 \times 10^{4} / \mu \mathrm{L}$ and $\mathrm{MCH}<30 \mathrm{pg}$ in the iron deficiency $(+)$ group $(\mathrm{n}=48,[44 \%])$ and iron deficiency $(-)$ groups $(\mathrm{n}=61$, $[21 \%])$, the proportion of patients with $\mathrm{MCH}<30 \mathrm{pg}$ and $\mathrm{RBC}>350 \times 10^{4} / \mu \mathrm{L}$ in iron deficiency $(+)$ group was significantly higher than in the iron deficiency $(-)$ group $(p<0.0001)$.

Table 1. Baseline and follow-up laboratory data of group according to the distribution of MCH and RBC.

\begin{tabular}{llll}
\hline Clinical variable & Group I (n=177) & Group II (n=217) & p-value \\
\hline Age, years & $71.9(11.1)$ & $70.5(12.2)$ & 0.246 \\
Sex (man/woman) & $100 / 77$ & $134 / 83$ & 0.304 \\
Dialysis duration, years & $11.1(5.8-19.2)$ & $9.8(5.4-16.4)$ & 0.213 \\
Survival, n (\%) & $152(86)$ & $159(73)$ & 0.00275 \\
Duration of survival period, day & $1069(174)$ & $975(286)$ & 0.000871 \\
Diabetes mellitus, $\mathrm{n}(\%)$ & $68(38)$ & $85(39)$ & 0.917 \\
History of cardiovascular disease, $\mathrm{n}(\%)$ & $40(22)$ & $49(23)$ & 0.999 \\
Dry weight, $\mathrm{kg}$ & $54.2(12.6)$ & $53.2(12.8)$ & 0.989 \\
Body mass index, $\mathrm{kg} / \mathrm{m}^{2}$ & $21.3(3.7)$ & $21.5(4.1)$ & 0.493 \\
Mode (HD/Online HDF) & $162 / 15$ & $203 / 14$ & 0.447 \\
Heamodialysis time, $\mathrm{hr}$ & $4.4(0.6)$ & $4.3(0.6)$ & 0.378 \\
\hline
\end{tabular}




\begin{tabular}{|c|c|c|c|}
\hline Clinical variable & Group I (n=177) & Group II $(\mathrm{n}=217)$ & p-value \\
\hline Systolic blood pressure before $\mathrm{HD}, \mathrm{mm} \mathrm{Hg}$ & $140.2(25.1)$ & $147.3(22.2)$ & 0.0611 \\
\hline Diastolic blood pressure before $\mathrm{HD}, \mathrm{mm} \mathrm{Hg}$ & $72.1(15.8)$ & $74.1(15.1)$ & 0.149 \\
\hline Hemoglobin levels, g/dl & $10.8(0.4)$ & $11.1(0.5)$ & $<0.0001$ \\
\hline Red blood cells, $104 / \mu \mathrm{L}$ & $331.6(13.3)$ & $375.1(25.1)$ & $<0.0001$ \\
\hline Mean corpuscular hemoglobin, pg & $32.6(1.2)$ & $29.8(2.1)$ & $<0.0001$ \\
\hline Mean corpuscular volume, fL & $99.1(92.2)$ & $92.3(5.3)$ & $<0.0001$ \\
\hline Mean corpuscular hemoglobin concentration, $\%$ & $32.9(0.9)$ & $32.3(1.0)$ & $<0.0001$ \\
\hline Serum ferritin levels, ng/dL & $105.5(66.3-164.3)$ & $75.0(32.2-121.0)$ & $<0.0001$ \\
\hline Serum iron levels, $\mu \mathrm{g} / \mathrm{dL}$ & $58.2(23.2)$ & $57.6(25.1)$ & 0.459 \\
\hline Transferrin saturation, $\%$ & $25.6(10.0)$ & $22.8(9.4)$ & 0.0023 \\
\hline Total iron binding capacity, $\mu \mathrm{g} / \mathrm{dL}$ & $236.0(49.2)$ & $248.8(51.3)$ & 0.0263 \\
\hline Unsaturated iron binding capacity, $\mu \mathrm{g} / \mathrm{dL}$ & $177.9(51.6)$ & $191.2(54.4)$ & 0.0556 \\
\hline Serum albumin levels, $\mathrm{g} / \mathrm{dL}$ & $3.5(0.4)$ & $3.6(0.4)$ & 0.0707 \\
\hline Blood urea nitrogen, $\mathrm{mg} / \mathrm{dL}$ & $59.0(15.3)$ & $59.9(14.3)$ & 0.454 \\
\hline Serum creatinine, $\mathrm{g} / \mathrm{dL}$ & $9.5(2.5)$ & $9.6(2.4)$ & 0.421 \\
\hline Serum calcium, mg/dL & $8.9(0.7)$ & $8.7(0.6)$ & 0.867 \\
\hline Serum inorganic phosphorus, $\mathrm{mg} / \mathrm{dL}$ & $4.8(1.0)$ & $4.8(1.1)$ & 0.555 \\
\hline Serum hs-CRP, mg/dl & $0.32(0.69)$ & $0.54(0.95)$ & $<0.0001$ \\
\hline Kt/Vurea & $1.84(0.36)$ & $1.80(0.33)$ & 0.292 \\
\hline ESA, IU/week & $1872(450)$ & $1933(466)$ & 0.187 \\
\hline Erythropoietin resistance index & $4.9(0.3-7.6)$ & $4.1(2.5-6.5)$ & 0.0109 \\
\hline Geriatric nutritional risk index & $91.1(8.2)$ & $92.2(7.6)$ & 0.18 \\
\hline
\end{tabular}

Abbreviations: HD, hemodialysis; HDF, hemodiafiltration; hs-CRP, high-sensitivity C-reactive protein; ESA, erythropoiesis stimulating agent. Patients were divided into two groups: Group I, $\mathrm{MCH} \geq 30 \mathrm{pg}$ and $\mathrm{RBC} \leq 350 \times 10^{4} / \mu \mathrm{L}$; Group II, $\mathrm{MCH}<30 \mathrm{pg}$ and $\mathrm{RBC}>350 \times 10^{4} / \mu \mathrm{L}$.

Table 2. Cox hazard analysis for all-cause mortality.

\begin{tabular}{lll}
\hline Clinical variable & Hazard ratio (95\% CI) & $p$-value \\
\hline Mean age, yr & $0.99(0.98-1.02)$ & 0.9873 \\
Sex & $1.01(0.64-1.58)$ & 0.9748 \\
Dialysis duration, years & $0.98(0.95-1.01)$ & 0.2657 \\
Diabetes mellitus & $0.79(0.48-1.33)$ & 0.3803 \\
History of cardiovascular disease & $0.77(0.43-1.36)$ & 0.3658 \\
Body mass index, $\mathrm{kg} / \mathrm{m}^{2}$ & $0.92(0.81-1.04)$ & 0.1767 \\
Serum albumin concentration, g/dL & $0.21(0.04-1.16)$ & 0.0729 \\
Serum hs-CRP, $\mathrm{mg} / \mathrm{dL}$ & $1.40(1.21-1.62)$ & $<0.0001$ \\
$\mathrm{Kt} / \mathrm{V}_{\text {ure }}$ & $1.24(0.62-2.45)$ & 0.5449 \\
\hline
\end{tabular}

Abbreviations: hs-CRP, high-sensitivity C-reactive protein; CI, confidence interval.

\section{Discussion}

We assessed the association between the distributions of $\mathrm{MCH}$ and $\mathrm{RBC}$ in a 3-year mortality period among hemodialysis patients retrospectively. We divided the patients into two groups based on the $\mathrm{MCH}$ and $\mathrm{RBC}$ values; patients with $\mathrm{MCH} \geq 30 \mathrm{pg}$ but $<35 \mathrm{pg}$ and $\mathrm{RBC} \leq 350 \times 10^{4} / \mu \mathrm{L}$ (Group I, $\mathrm{n}=177)$, and patients with $\mathrm{MCH}<30 \mathrm{pg}$ and $\mathrm{RBC}>350 \times 10^{4} / \mu \mathrm{L}$ (Group II, $\mathrm{n}=217$ ). In this study, the primary finding from this study is that $\mathrm{MCH}<30 \mathrm{pg}$ and $\mathrm{RBC}>350 \times 10^{4} / \mu \mathrm{L}$ in patients on regular thrice weekly HD treatment is associated with an increased long-term risk of the death (Figure 1). The secondary findings were that as a result of comparing the iron profiles of these two groups, the percentage of patients with high iron-deficiency in group II was significantly higher than that in group I. These results suggested that iron was deficient in group II (Figure 2). The proportion of patients with $\mathrm{MCH}<30 \mathrm{pg}$ and $\mathrm{RBC}>350 \times 10^{4} / \mu \mathrm{L}$ was significantly higher in patients with absolute iron deficiency than in patients without absolute iron deficiency. This result suggests that absolute iron deficiency is more common in patients with high RBCs.

Table 3. Distribution of Group I and II according to serum ferritin levels and TSAT.

\begin{tabular}{llll}
\hline Category & Group I $(\mathbf{n = 1 7 7})$ & Group II $(\mathbf{n}=\mathbf{2 1 7})$ & $\boldsymbol{p}$-value \\
\hline Q1 $($ TSAT $\geq 20 \%$ and Ferritin $\geq 100 \mathrm{ng} / \mathrm{mL})$ & $50(28 \%)$ & $25(11 \%)$ & $p<0.0001$ \\
Q2 (TSAT $\geq 20 \%$ and Ferritin $<100 \mathrm{ng} / \mathrm{mL})$ & $32(18 \%)$ & $56(26 \%)$ & 0.3721 \\
Q3 (TSAT $<20 \%$ and Ferritin $<100 \mathrm{ng} / \mathrm{mL})$ & $9(5 \%)$ & $46(21 \%)$ & $p<0.0001$ \\
Q4 (TSAT $<20 \%$ and Ferritin $\geq 100 \mathrm{ng} / \mathrm{mL})$ & $86(49 \%)$ & $90(42 \%)$ & 0.01899 \\
\hline
\end{tabular}

Abbreviations: hs-CRP, high-sensitivity C-reactive protein; CI, confidence interval.

Regarding the relationship between TSAT, which is one of the iron metabolism markers, and mortality, it has been 
reported that the prognosis is good in the case of TSAT is $20-40 \%$, and the prognosis is poor in the case of TSAT is $20 \%$ or less. Hayashi et al. reported that patients with low TSAT had high cardiothoracic ratio (CTR) [6. Hayashi T,]. That high CTR was poor prognosis has been reported in the MBD-5D study and the Q-cohort study [7, 8]. Regarding TSAT, it is reported that the prognosis is the best when the TSAT value is 20 to $40 \%$, and the prognosis is poor in case of TSAT $\leq 20 \%$. [9. Koo HM]. Although there is no report on the prognosis of $\mathrm{MCH}$, it is speculated that setting $\mathrm{MCH}$ to $30 \mathrm{pg}$ or more is not wrong from the viewpoint of prognosis, considering that $\mathrm{MCH}$ correlates with TSAT.

According to the report of Hatamizadeh et al., the prognosis with TSAT $30-40 \%$ was best regardless of the presence or absence of polycystic kidney disease (PKD), and the prognosis with TSAT $\leq 20 \%$ was poor. Moreover, they reported that the hazard ratio was lower for serum ferritin levels 100-800 $\mathrm{ng} / \mathrm{mL}$ than for less than $100 \mathrm{ng} / \mathrm{mL}$ with U-curve. [10]. Although it is based on US data, iron deficiency should not be neglected. For $\mathrm{RBC}>350 \times 10^{4} / \mu \mathrm{L}$ or higher, $\mathrm{MCH}$ is low, and because there are many patients with absolute iron deficiency, $\mathrm{RBC}$ is $350 \times 10^{4} / \mu \mathrm{L}$ or less, $\mathrm{MCH}$ is $30 \mathrm{pg}$ or more, TSAT is at least $20 \%$ or more, and ferritin is $100 \mathrm{ng} / \mathrm{mL}$ or less. Instead, the management goal is to avoid absolute iron deficiency. [11]. Assuming that the width of TSAT is $20-40 \%$, it can be seen from Figure 3 that quite a few patients with $\mathrm{MCH}$ of $30 \mathrm{pg}$ or more and TSAT $20-40 \%$. If TSAT is 20 to $40 \%$, the regression equation of $\mathrm{MCH}$ and TSAT is within this range, and it seems that the fit of $\mathrm{MCH} 30 \mathrm{pg}$ or more is better. Meanwhile, hyperferritinemia is reportedly a risk factor for poor prognosis and generally has the best prognosis in patients with ferritin levels $<100 \mathrm{ng} / \mathrm{mL}$ [12].

Iron plays an important role in energy metabolism, and iron deficiency has been reported to increase FGF-23 and cause left ventricular hypertrophy [8]. Red cell distribution width (RDW) increase was found to be an independent risk factor for prognosis [13, 14]. Furthermore, RDW increased in iron deficiency and RDW decreased after oral administration of ferric citrate [15]. These results suggest that the poor prognosis in the high $\mathrm{RBC}$ group may be due to iron deficiency.

TSAT is a value obtained by dividing the serum iron levels by TIBC, and the TSAT decreases when the serum iron levels are low. $\mathrm{MCH}$ reflects the amount of iron used during the period corresponding to $\mathrm{RBC}$ life, and $\mathrm{MCH}$ is reduced if iron is not fully utilized due to iron deficiency. Therefore, TSAT and $\mathrm{MCH}$ are considered to show a positive correlation; in fact, our results showed a significant positive correlation (Figure 3 ). TSAT $20-40 \%$, which has a good prognosis in the literature, generally matched $\mathrm{MCH} 30-35 \mathrm{pg}$. The $\mathrm{Hb}$ levels generally provide the value of $\mathrm{RBC}$ and iron status because $\mathrm{MCH}$ is derived from the $\mathrm{Hb}$ divided by $\mathrm{RBC}$. $\mathrm{MCH}$ depends on the size and concentration of erythrocytes. Thus, RBC and $\mathrm{MCH}$ values depend on ESA and iron doses, respectively. $\mathrm{Hb}$ is expressed as the product of $\mathrm{RBC}$ and $\mathrm{MCH}$, and the upper limit of $\mathrm{MCH}$ is approximately $35 \mathrm{pg}$. Therefore, if $\mathrm{RBC}$ is reduced to approximately $350 \times 10^{4} / \mu \mathrm{L}$ or less, even if $\mathrm{MCH}$ increases to $35 \mathrm{pg}$ by iron administration, theoretically, $\mathrm{Hb}$ levels do not exceed $12 \mathrm{~g} / \mathrm{dL}$. To prevent $\mathrm{Hb}$ levels from falling below $10 \mathrm{~g} / \mathrm{dL}$, at least RBC must be $300 \times 10^{4} / \mu \mathrm{L}$ or more, or $\mathrm{MCH}$ must be $30 \mathrm{pg}$ or more. When $\mathrm{MCH}$ rises to a maximum of $35 \mathrm{pg}$ due to iron supplementation, $\mathrm{Hb}$ levels theoretically does not exceed $12 \mathrm{~g} / \mathrm{dL}$ at RBC less than $350 \times 10^{4} / \mu \mathrm{L}$; however, when $\mathrm{RBC}$ exceeds $350 \times 10^{4} / \mu \mathrm{L}$, the more $\mathrm{RBC}$, the more $\mathrm{Hb}$ levels tends to exceed $12 \mathrm{~g} / \mathrm{dL}$. If $\mathrm{RBC}$ and $\mathrm{MCH}$ are adjusted with ESAs and iron, respectively, the management target values are RBC $300-350 \times 10^{4} / \mu \mathrm{L}$ for ESA and $\mathrm{MCH} 30$ to $35 \mathrm{pg}$ for iron. If RBC is less than $300 \times 10^{4} / \mu \mathrm{L}$, increase $\mathrm{ESA}$, and if $\mathrm{RBC}$ is more than $350 \times 10^{4} / \mu \mathrm{L}$, decrease ESA. When $\mathrm{MCH}$ is low, it becomes an index of iron deficiency anemia, and when MCH is less than $30 \mathrm{pg}$, supplementation with iron can be used to maintain $\mathrm{Hb}$ levels $10-12 \mathrm{~g} / \mathrm{dL}$ recommended by the Japanese guidelines for renal anemia in chronic kidney disease. As there have been no reports on the prognosis of $\mathrm{MCH}$ and $\mathrm{RBC}$ distribution, the study therefore significantly contributes to the lack in the literature. Further, it would be of great interest to the readership as the novel findings provide valuable guiding information for clinical practice and even basis for future researches.

There are some limitations in our study. The observed associations were obtained by using a cross-sectional design, which does not permit us to draw casual conclusions with confidence. Therefore, more prospective studies to determine whether the mortality among HD patients are associated with $\mathrm{MCH}$ and RBC status are needed. In this study, we did not consider the association between iron status and dietary habits; therefore, we cannot exclude the possibility that the observed associations had to do with dietary intake of iron. Iron status and dietary iron intake (e.g., iron-based phosphorus binders) should be considered in future investigation of associations between iron and anemia status among HD patients. This observational retrospective study allowed only limited conclusions. Hence, we could not establish a cause-and-effect relationship between iron metabolism and anemia. Since serum ferritin is both an iron storage protein and an acute phase reactant, further prospective studies are needed for the comparisons of the clinical presentation of anemia and serum ferritin. The several covariates used in multivariate analysis are not only directly influenced by response variables but are also affected by other covariates which often hinder analysis. In this study, we did not take into the consideration the patients' BMI, psychosocial dimensions, such as economic status, family support, gender differences, reproductive age and menopause, and some other emotional stresses related to depressive symptoms. Previous study reported that there was a significant difference in the levels of serum ferritin concentrations between genders in a Japanese population [16]. In future research, the effect of confounding the patient background factors such as diseases associated with depression, history of stroke and other neurological conditions, bed bound patients, and even social conditions such as monthly income and family support should be disregarded. 


\section{Conclusion}

The condition to satisfy Hb levels $12 \mathrm{~g} / \mathrm{dL}$ could be fulfilled by a variety of combinations of $\mathrm{MCH}$ and $\mathrm{RBC}$. This study indicates that maintaining $\mathrm{RBC} 300-350 \times 10^{4} / \mu \mathrm{L}$ and $\mathrm{MCH} 30$ to $35 \mathrm{pg}$ may not only achieve $\mathrm{Hb}$ level management not exceeding $12 \mathrm{~g} / \mathrm{dL}$, but also have a positive impact on prognosis.

\section{Disclosure Statement}

All authors declare no competing financial interests.

\section{Statement of Ethics}

All procedures performed in studies involving human participants were in accordance with the ethical standards of the institutional and national research committees at which the studies were conducted (IRB approval number NCT04227158) and with the 1964 Helsinki declaration and its later amendments or comparable ethical standards.

\section{Funding Sources}

Not applicable.

\section{Author Contributions}

YT designed the study. NS and $\mathrm{YH}$ analyzed and interpreted the data. TN, TT, and YM drafted the article and revised it. All authors participated in drafting the article or revising it critically for important intellectual content. All authors read and approved the final manuscript.

\section{Acknowledgements}

The authors thank the staff of the dialysis center at Tojinkai Hospital for their help with data collection.

\section{References}

[1] Langston RD, Presley R, Flanders WD, McClellan WM. Renal insufficiency and anemia are independent risk factors for death among patients with acute myocardial infarction. Kidney Int. 2003 Oct; 64 (4): 1398-405.

[2] Yamamoto Y, Nishi S, Tomo T, Masakane I, Saito K, et al: 2015 Japanese Society for Dialysis Therapy: guidelines for renal anemia in chronic kidney disease. Renal Replacement Ther $2017 ; 3: 36$.

[3] Daugirdas JT, Greene T, Depner TA, Chumlea C, Rocco MJ, Chertow GM, et al. Anthropometrically estimated total body water volumes are larger than modeled urea volume in chronic hemodialysis patients: effects of age, race, and gender. Kidney Int 2003 Sep; 64 (3): 1108-1119.
[4] Fishbane S, Berns JS. Hemoglobin cycling in hemodialysis patients treated with recombinant human erythropoietin. Kidney Int. 2005 Sep; 68 (3): 1337-43.

[5] Examination Committee of Criteria for 'Obesity Disease' in Japan, Japan Society for the Study of Obesity. New criteria for 'obesity disease' in Japan. Circ J. 2002 Nov; 66 (11): 987-92.

[6] Hayashi T, Tanaka Y, Iwasaki M, Hase H, Yamamoto H, Komatsu Y, et al. Association of Circulatory Iron Deficiency With an Enlarged Heart in Patients With End-Stage Kidney Disease. J Ren Nutr. 2019 Jan; 29 (1): 39-47.

[7] Ogata H, Kumasawa J, Fukuma S, Mizobuchi M, Kinugasa E, Fukagawa M, et al. The cardiothoracic ratio and all-cause and cardiovascular disease mortality in patients undergoing maintenance hemodialysis: results of the MBD-5D study. Clin Exp Nephrol. 2017 Oct; 21 (5): 797-806.

[8] Yotsueda R, Taniguchi M, Tanaka S, Eriguchi M, Fujisaki K, Torisu K, et al. Cardiothoracic Ratio and All-Cause Mortality and Cardiovascular Disease Events in Hemodialysis Patients: The Q-Cohort Study. Am J Kidney Dis. 2017 Jul; 70 (1): 84-92.

[9] Koo HM, Kim CH, Doh FM, Lee MJ, Kim EJ, Han JH, et al. The relationship of initial transferrin saturation to cardiovascular parameters and outcomes in patients initiating dialysis. PLoS One. 2014 Feb 5; 9 (2): e87231.

[10] Hatamizadeh P, Ravel V, Lukowsky LR, Molnar MZ, Moradi H, Harley $\mathrm{K}$, et al. Iron indices and survival in maintenance hemodialysis patients with and without polycystic kidney disease. Nephrol Dial Transplant. 2013 Nov; 28 (11): 2889-98.

[11] Karaboyas A, Morgenstern H, Pisoni RL, Zee J, Vanholder R, Jacobson SH, et al. Association between serum ferritin and mortality: findings from the USA, Japan and European Dialysis Outcomes and Practice Patterns Study. Nephrol Dial Transplant 2018 Dec; 33 (12): 2234-44.

[12] Kuragano T, Matsumura O, Matsuda A, Hara T, Kiyomoto H, Murata T, et al. Association between hemoglobin variability, serum ferritin levels, and adverse events/mortality in maintenance hemodialysis patients. Kidney Int. 2014 Oct; 86 (4): 845-54.

[13] Fukasawa H, Ishibuchi K, Kaneko M, Niwa H, Yasuda H, Kumagai H, et al. Red Blood Cell Distribution Width Is Associated With All-Cause and Cardiovascular Mortality in Hemodialysis Patients. Ther Apher Dial. 2017 Dec; 21 (6): 565-71.

[14] Salvagno GL, Sanchis-Gomar S, Picanza A, Lippi G. Red blood cell distribution width: A simple parameter with multiple clinical applications. Crit Rev Clin Lab Sci. 2015; 52: 86-105.

[15] Yokoyama K, Fukagawa M, Akiba T, Nakayama M, Ito K, Hanaki K, et al. Randomised clinical trial of ferric citrate hydrate on anaemia management in haemodialysis patients with hyperphosphataemia: ASTRIO study. Sci Rep. 2019 Jun; 9 (1): 8877.

[16] Yi S, Nanri A, Poudel-Tandukar K, Nonaka D, Matsushita Y, Hori A, et al. Association between serum ferritin concentrations and depressive symptoms in Japanese municipal employees. Psychiatry Res. 2011; 189 (3): 368-72. 